University of Nebraska - Lincoln

DigitalCommons@University of Nebraska - Lincoln

Civil Engineering Faculty Publications

Civil Engineering

$1-2012$

\title{
Head Ejection during Barrier Impacts
}

Scott K. Rosenbaugh

University of Nebraska-Lincoln, srosenbaugh2@unl.edu

Ronald K. Faller

University of Nebraska - Lincoln, rfaller1@unl.edu

Dean L. Sicking

University of Nebraska - Lincoln, dsicking1@unl.edu

Follow this and additional works at: https://digitalcommons.unl.edu/civilengfacpub

Part of the Civil Engineering Commons

Rosenbaugh, Scott K.; Faller, Ronald K.; and Sicking, Dean L., "Head Ejection during Barrier Impacts" (2012). Civil Engineering Faculty Publications. 43.

https://digitalcommons.unl.edu/civilengfacpub/43

This Article is brought to you for free and open access by the Civil Engineering at DigitalCommons@University of Nebraska - Lincoln. It has been accepted for inclusion in Civil Engineering Faculty Publications by an authorized administrator of DigitalCommons@University of Nebraska - Lincoln. 


\title{
Head Ejection during Barrier Impacts
}

\author{
Scott K. Rosenbaugh, ${ }^{1}$ Ronald K. Faller, Ph.D, P.E., M.ASCE, ${ }^{2}$ and Dean L. Sicking, Ph.D, P.E., M.ASCE ${ }^{3}$ \\ 1. Research Associate Engineer, 2200 Vine St., 130 Whittier Research Center, University of Nebraska-Lincoln, Lincoln, NE 68583; \\ Corresponding author, email srosenba@unlserve.unl.edu \\ 2. Research Assistant Professor, 2200 Vine St., 130 Whittier Research Center, University of Nebraska-Lincoln, Lincoln, NE 68583; \\ email rfaller1@unl.edu \\ 3. Professor, MwRSF Director, 2200 Vine St., 130 Whittier Research Center, University of Nebraska-Lincoln, Lincoln, NE 68583; \\ email dsicking@unl.edu
}

\begin{abstract}
During oblique vehicular impacts with longitudinal barriers, an occupant's head is often ejected out of a side window. When this occurs, the occupant's head can contact the barrier or an object attached thereto. This impact event, often termed head slap, normally produces a serious injury or fatality. Roadside barriers and any attached hardware should be designed with sufficient offset at the top to preclude head slap for most impact conditions. The goal of this study was to identify the extent of head ejection that can be expected during high-speed crashes with longitudinal barriers. High-speed videos of full-scale vehicle crash tests were analyzed to determine the occupant head trajectories. Videos of 11 full-scale crash tests with both small cars and pickup trucks were analyzed to produce a head ejection envelope to encompass all head trajectories observed in the tests. Adjustments were made to the envelope to account for varying vehicle heights, seated passenger heights, and vehicle movements during impact. Two head ejection envelopes were created; one to encompass ejections from occupants at or below the 5oth percentile male seated height and the other to encompass ejections from occupants at or below the 95th percentile male seated height. The final head ejection envelopes were constructed as a template for designing future barrier systems and for determining the safe placement of fixed objects on top of or behind rigid parapets.
\end{abstract}

Keywords: highway and road design, safety, barriers, roadside hazards

\section{Introduction}

Historically, thousands of full-scale vehicle crash tests have been performed on various longitudinal barrier systems by using passenger-type vehicles. For many of these high-speed, oblique impact events, dummies were placed within the occupant compartment to study dummy behavior and/or to accentuate vehicular instabilities. Often, the dummy's head has been forced out of the vehicle's window by high accelerations imparted to the vehicle during the impact with a rigid or very stiff longitudinal barrier. When this event occurs, the head is susceptible to striking the barrier or a fixed object found above or behind the barrier. This event is called a head slap and can result in serious injury, or even death.

In 2004, Giavotto reported that side windows were the most prominent place for head ejection, especially in crashes with safety barriers. The same study also found that accidents involving this type of ejection were 11.7 times more likely to involve a fatality than accidents involving safety barriers in general (Giavotto 2004). Clearly, the risk of head slap needs to be minimized.

Head slap can be eliminated by ensuring that barrier components and attachments are not positioned where an occupant's ejected head could strike them. There have been prior efforts to mitigate head slap against longitudinal barriers by removing the top-front corner of tall barriers (Polivka et al. 2005). However, an extensive examination to identify all possible locations of an occupant's head during ejection has never been completed. The study described in this paper was undertaken to examine occupant head trajectories during side window ejections to identify exclusion regions around the top of a barrier where barrier com- ponents and attachments should be eliminated to reduce the risk of head slap.

\section{Research Objective}

The objective of the research project was to investigate the range of possible of head ejection trajectories during an ejection event arising from oblique vehicular impacts with a longitudinal barrier. The head ejection trajectories would then be used to identify an envelope to encompass all possible occupant head locations outside of the vehicle. The head ejection envelope could be used as a template for designing barriers and attachments to minimize the risk of head slap during vehicular impacts.

\section{Research Approach}

Unfortunately, it is impossible to gather head ejection displacement data from actual roadway accidents. Occupant head ejections are not always identified by police officers investigating traffic accidents. A combination of rebound off the door and the post impact trajectory of the vehicle usually propels the occupant back into the vehicle. Hence, it is not always clear that a head ejection has occurred when the investigating officer arrives at a scene. Further, even when head ejection is identified, most accident reports do not contain a code describing head slap. As result, it is impossible to identify head slap from existing crash databases. Thus, it was necessary to collect the needed data from another resource.

Full-scale crash testing provided the film and video documentation necessary for studying the head ejection phenomenon. Historically, crash tests have been recorded by using several 
high-speed film and/or video cameras which provide multiple view points. Also, both the National Cooperative Highway Research Program (NCHRP) Report No. 350 "Recommended Procedures for the Safety Performance Evaluation of Highway Features" (Ross et al. 1993) and its predecessor, NCHRP Report No. 230 (Michie 1981), have specified that a 5oth percentile male dummy be used for all small car barrier tests and also provided an option for their use in large sedan and pickup truck tests. The displacement of a dummy's head outside of a vehicle was tracked by using the high-speed films and videos obtained from these full-scale crash tests. All these tests involved rigid or nearly rigid barrier systems impacted under standardized test conditions.

NCHRP Report No. 350 recommends the use of a Hybrid III dummy when performing small car crash tests. The Hybrid III dummy was intended for use in simulating frontal impact events and, thus, was not considered capable of accurately simulating lateral body movements. However, the Hybrid III dummy has been believed to be generally capable of simulating dummy movements in oblique vehicle-barrier collisions. Thus, the Hybrid III dummy was believed to provide a reasonable measure of the extent a head can be ejected through a side window. These full-scale vehicle crash tests represent the best available method to determine the extent of lateral head ejection.

After the head trajectory data was recorded, measurements from all tests were combined to illustrate the range of possible occupant head locations outside of various vehicle models. An envelope was then created encompassing all the head ejection data points from the crash test films and videos. A significant number of head ejection events were documented from full-scale crash tests with small cars and pickup trucks. However, midsize vehicles, such as sedans and light sport utility vehicles (SUVs), were not required by any of the historical crash test procedures and have been rarely used in full-scale barrier testing. To consider head ejection in vehicles not typically used in crash testing programs, the head displacement data was interpolated from that collected for small cars and pickup trucks. The head ejection envelope was then modified to include the predicted displacement data from midsize vehicles. This final head ejection envelope should represent the boundaries of head displacement outside of the side windows for full-range of passenger vehicles.

\section{Crash Test Video Selection}

This study was limited to passenger vehicle impacts into rigid or nearly rigid barriers for two reasons. First, the roadside area behind flexible barriers is typically clear of fixed objects to prevent secondary impacts. Further, semirigid or flexible roadside barriers normally do not reach above the bottom of the windows of small passenger cars, and ancillary hardware is seldom attached to these barriers. Thus, virtually no risk of head slap exists for semirigid and flexible barriers. Second, rigid barriers produce much higher lateral accelerations during an impact than more flexible barriers. High acceleration events produce much greater head ejection, i.e., head displacement out of the side window. Clearly, the boundaries of the head ejection envelope would be defined by the more severe events associated with rigid or nearly rigid barriers.

Barrier shape also plays a key factor in the potential for head ejection. Vehicle impacts into rigid systems with a mountable curb at the base, such as New Jersey and F-shape concrete barriers, result in the vehicle climbing up the face and rolling away from the barrier. As an impacting vehicle climbs the barrier, head slap becomes less of a concern because occupant's heads are lifted above the top of the barrier. Therefore, this study was limited to crash tests involving impacts into rigid barriers with non-mountable faces, such as vertical and open concrete rails.

Note that crash testing has demonstrated that unrestrained dummies can be completely ejected from the vehicle during barrier impacts. Clearly, complete occupant ejection during a highspeed barrier impact is very dangerous, regardless of the shape of the barrier. Further, it would be impossible to develop a barrier shape that could safely accommodate these events. Thus, the research effort described in this paper was limited to crash tests that incorporated restrained dummies.

\section{Video Analysis Procedure}

All relevant and available films and videos of full-scale crash tests where head ejection was observed were obtained and, when necessary, converted into AVI format. Vehicle and dummy head movements were then analyzed on a frame by frame basis by using up to three camera viewpoints. Upstream, downstream, and overhead views allowed for the observation and measurement of the maximum lateral head ejection.

The bottom of the side window was used as the base point for all head motion measurements. This point was selected for two reasons. First, the individual vehicle heights were taken out of the analysis by basing the measurements from the bottom of the window. Thus, the measured head ejection could be applied to all vehicles, not just the specific test vehicle, by shifting the envelope up or down. Second, maximum head ejection usually occurred at approximately the same time that the vehicle became parallel with the barrier. The side of the vehicle, including the bottom of the window, would then be in direct contact with the barrier. In this situation, head displacements measured laterally out from the side window would extend beyond the face of the barrier. Hence, this reference point produced a head ejection envelope that could be applied directly to face in the barrier itself.

When gathering displacement data, both the lateral and vertical locations of the head during the impact event were necessary to define the head ejection envelope. The lateral displacement of the head out of the side window, paired with its vertical position, established a point representing the extent of head ejection on a $2 \mathrm{D}$ plane normal to the side of the vehicle. Since the time that the maximum head ejection occurred very near to the time when the vehicle became parallel to the barrier, this $2 \mathrm{D}$ plane was then assumed to be normal to the face of the barrier. An example of an ejected head, and the associated lateral and vertical displacement measurements, is depicted in Figure 1.

The head ejection envelope was defined by the maximum lateral and the lowest vertical head displacement. These two measurements were closely observed while tracking the path of the head as it was ejected out of the side window. Crash test videos showed that, during a head ejection event, a dummy's shoulder is normally pressed against the door and cannot move farther outward. Thus, head ejection was attributed to the rotation of the neck and shifting of the body. With body motion restricted by the safety belts, head displacement occurred as a result of neck and torso bending. Head and neck rotations were further limited by the dummy's physical neck structure and contact with the bottom of the side window. These limitations prevented the head from rotating past horizontal in the analyzed crash test videos. Thus, the maximum lateral and minimum vertical head positions normally were observed to occur simultaneously, and the critical head ejection position in each test was reached in only one frame. 


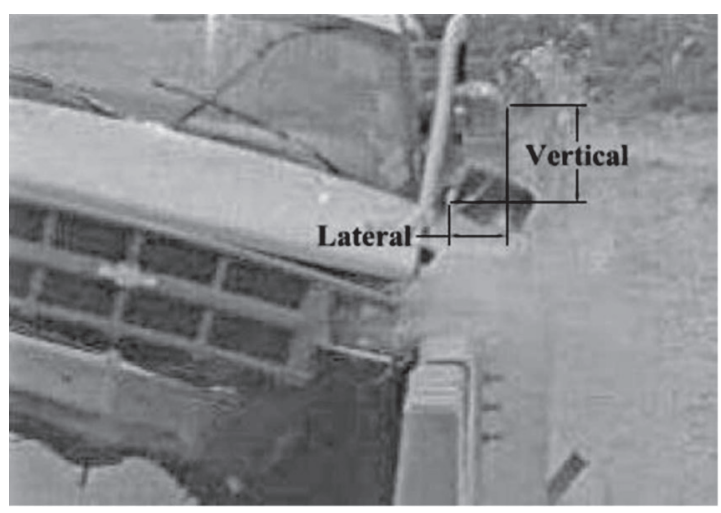

Figure 1. Lateral and vertical displacement measurements.

For the upstream and downstream camera views, the lateral and vertical distances from the bottom of the window were measured at three different points to define the contour of the ejected head. The three points on the head were the minimum vertical point, the maximum lateral point, and a point between the other two. These points are labeled point Nos. 1 through 3, as shown in Figure 2(a). Each head ejection measurement was repeated

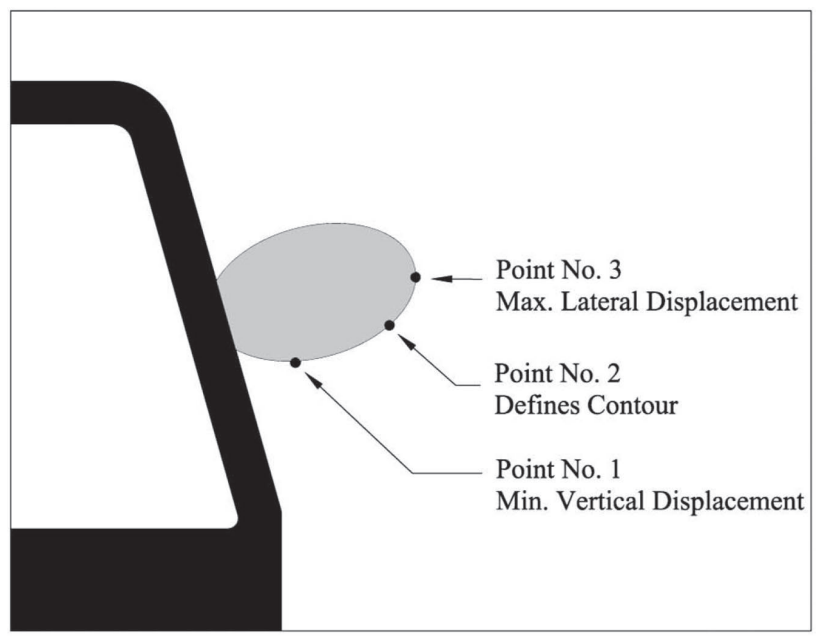

(a)

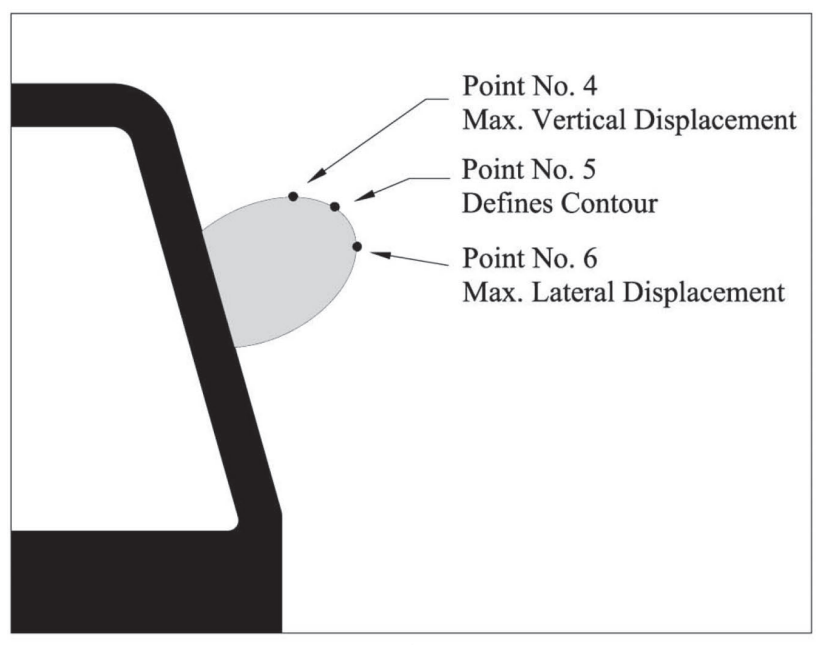

(b)

Figure 2. Location of tracked points: (a) maximum lateral displacement; (b) maximum vertical position.
10 times for every applicable view of the crash test. Thus, each upstream and downstream view resulted in 30 independent points describing the extreme location of a passenger's ejected head.

For the overhead view, only the maximum lateral displacement to a single point was measured. The average of the vertical measurements taken for the point of maximum lateral displacement, point No. 3, in the upstream and downstream views, was used as the vertical displacement for all 10 of the lateral measurements taken from the top view. This interpolation resulted in 10 data points describing the maximum lateral head displacement obtained from the overhead view.

Head ejection measurements were separated into two categories, one for small cars and another for pickup trucks. Different head displacements were expected for these vehicles because of the variations in seat orientation in the two vehicles. A pickup truck passenger is usually seated more upright and higher relative to the side window as compared to small car occupants. If a pickup occupant's shoulder does not contact the door, the head and neck can move closer to the side window before neck rotation begins. As a result, occupants of pickup trucks tend to experience larger lateral head excursions than those observed for small car passengers.

Although all head ejection measurements were taken relative to the bottom of the side window, it was recognized that small cars and pickup trucks have much different window heights, and, thus, have different origin locations. Therefore, all small car measurements were grouped together with one common origin, whereas the pickup truck measurements were given a different common origin. In doing so, head ejection envelopes were constructed separately for each vehicle class. These vehicle specific head ejection envelopes were later placed at the correct vertical positions according to vehicle side window heights to define the complete head ejection envelope.

\section{Head Ejection Measurements from Small Cars}

Eight full-scale crash tests were used to determine head ejection associated with small cars, as shown in Table 1 . These crash tests involved impacts with rigid longitudinal barriers performed according to the NCHRP Report No. 350 guidelines. The highspeed videos for each test clearly showed the contour of the dummy's head as it traveled outside of the vehicle. With only one exception, multiple camera views were utilized for each test. Although head ejection was also observed in many other small car crash tests, the test data had to be excluded because of obstruction of the camera views, or the extent of head ejection was insufficient to affect the bounds of the head ejection envelope.

The small cars evaluated in this study had similar vehicle dimensions, including the vertical height to the bottom of the side window. Additional information regarding the specific vehicles and the associated properties can be found elsewhere (Rosenbaugh 2007; Rosenbaugh et al. 2007). It was also determined that a front-seat occupant would be seated in a similar vertical and lateral position while riding in any of the small cars involved in the tests.

Note that small cars used in full-scale crash testing represent the smallest passenger vehicles on the roadway. With the exception of limited production sports cars, these vehicles also have the lowest driver height and window height. Therefore, small cars produce the lowest head ejection trajectory and effectively define the lower bounds of the head ejection envelope. As such, no upper bound was given to the envelope at this time. Larger vehicles must be used to define the upper portions of the head ejection envelope. 
Table 1. Crash Tests Used to Determine Head Ejection Envelope

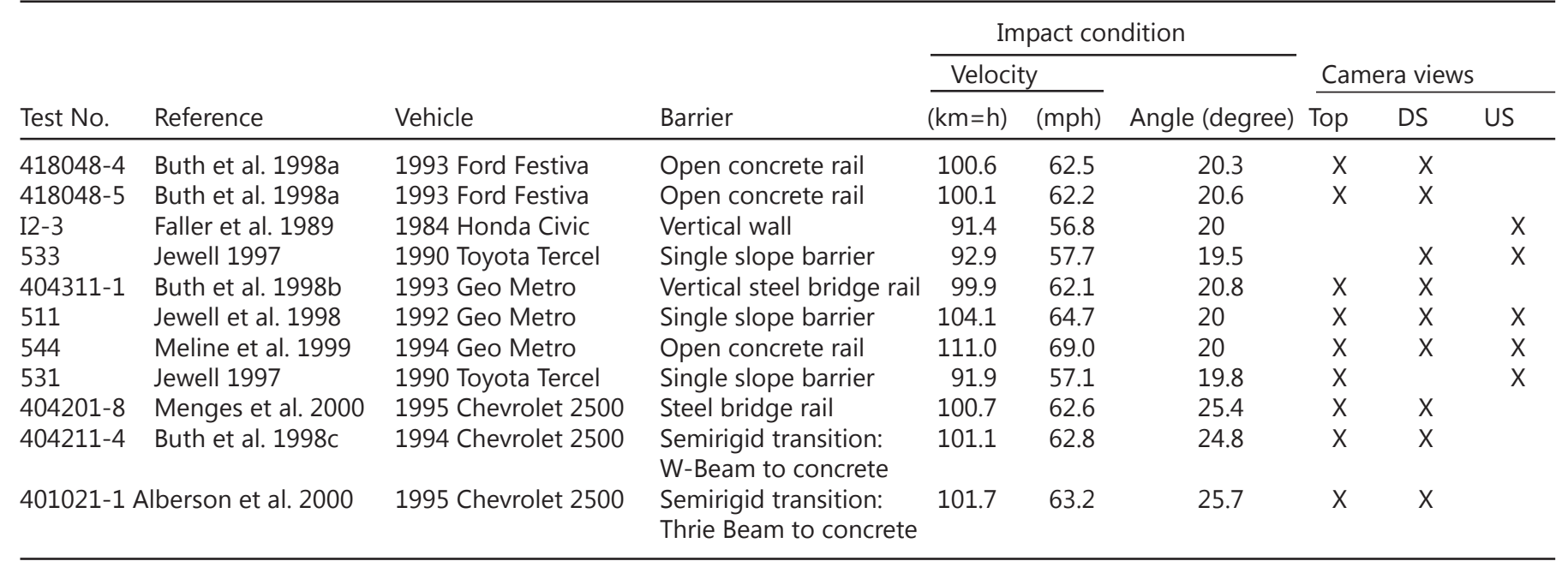

DS = downstream; US = upstream.

The resulting head ejection measurements from the eight small car crash tests were compiled into a single plot by using a common origin. An envelope consisting of segmented lines beginning at the origin, i.e., base of the window, was constructed by using all the head ejection measurements. This envelope constituted the area outside the side window of a small car that an ejected head may occupy during a crash. Figure 3 shows the constructed envelope represented by three segmented lines surrounding the combined data points from the small car tests.

\section{Head Ejection Measurements from Pickup Trucks}

NCHRP Report 350 does not recommend that a dummy be included in pickup truck crash tests into longitudinal barriers. As a result, a limited number of crash test videos were found that showed head ejection out of pickup trucks during rigid and semirigid barrier impacts. Therefore, pickup truck crash tests with guardrail transitions were included in the head ejection analysis to obtain additional data points. Even including approach guardrail transitions, only three full-scale crash tests were available for determining head ejection from pickup truck impacts into longitudinal barriers, as shown in Table 1.

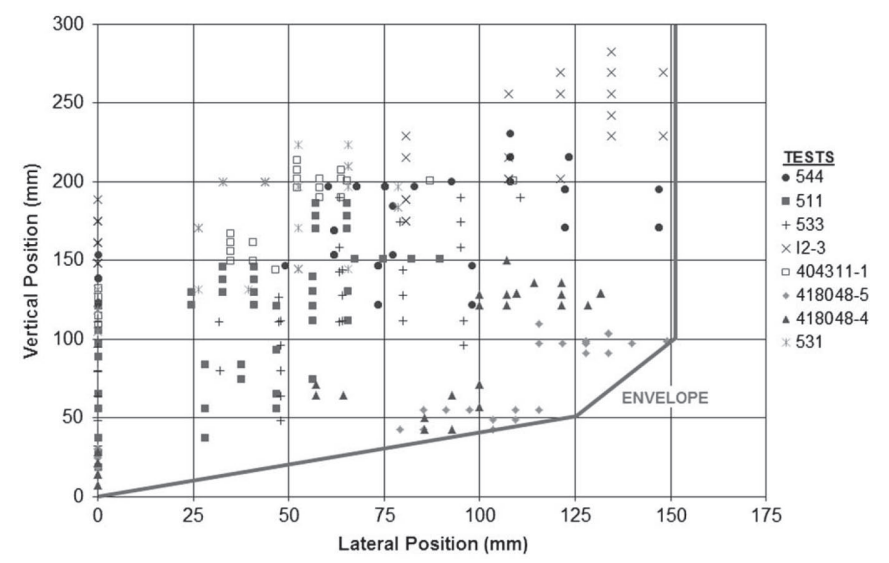

Figure 3. Head ejection envelope based on small car data
The analysis procedure used to determine head ejection for small car impacts was also implemented for pickup truck impacts. This analysis included the determination of the maximum lateral and minimum vertical head positions. In addition to those measurements, the maximum vertical position of the head was also necessary to define the upper bound of the head ejection envelope. An analysis of the pickup truck tests revealed that the dummy's head was higher on its return path back into the pickup truck's cab. Often, the head actually impacted the top door frame before returning into the cab. Thus, the measurements for the upper bounds on the head ejection envelope were taken shortly after the maximum lateral displacement had occurred but before the head re-entered the cab.

Three different points on the dummy's head were tracked after maximum lateral displacement by using the downstream camera view. These tracking points are shown in Figure 2(b) and are depicted as point Nos. 4 through 6. Point No. 6 was similar to point No. 3 in the previous analysis and corresponded to the maximum lateral position of the head. Point No. 4 was the maximum vertical position, and point No. 5 was used to define the head contour between the other two points. Point Nos. 4 through 6 were tracked to capture the head's motion from the maximum lateral head position until the head moved back into the cab. The motion of the head was followed until the vehicle door was no longer in contact with the barrier, sometimes preceding a complete return of the head into the cab.

Note that most full-size pickup trucks have similar dimensions, including the vertical height to the bottom of the side window and occupant seating positions. Additional pickup truck details have been previously reported, and, thus, were excluded from this paper (Rosenbaugh 2007; Rosenbaugh et al. 2007). Therefore, the resulting head ejection measurements were similar in nature and were measured from the same origin.

A head ejection envelope was constructed by using the measurements acquired from the pickup truck data analysis by using a similar methodology implemented with the small car impacts. However, the pickup truck head ejection envelope was considered as two independent boundaries. One boundary defined the maximum lateral head ejection and minimum vertical position of the head, whereas the second boundary defined the maximum vertical position of the head. The two pickup truck boundaries were considered separately because each origin was placed 


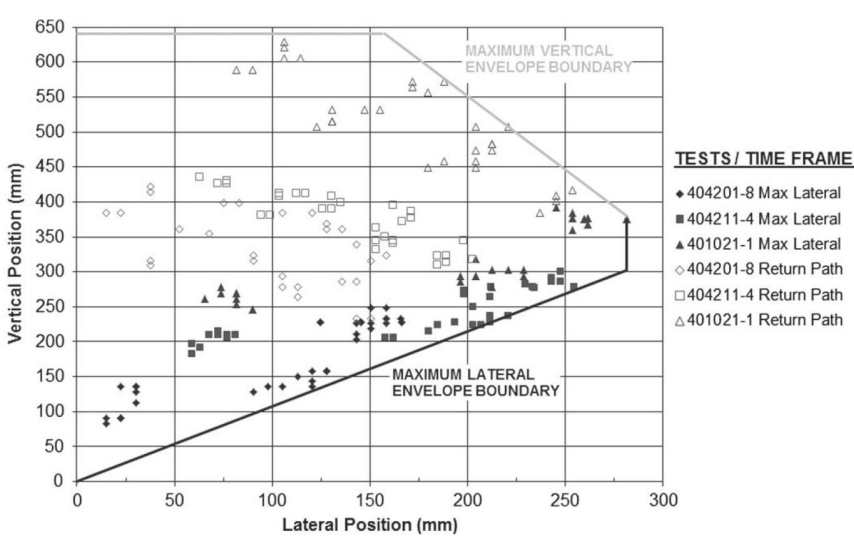

Figure 4. Head ejection envelope on the basis of pickup truck data

in a different vertical location corresponding to different vehicle heights, as discussed later. The boundaries of the head ejection envelope, which surrounds the combined pickup truck test data points, are shown in Figure 4.

\section{Combined Head Ejection Envelopes}

To create a combined head ejection envelope for all passenger vehicles, the individual envelopes determined from the small car and pickup truck tests had to be combined appropriately. Recall, that the time of maximum lateral head ejection nearly coincides with the time that the vehicle becomes parallel with the barrier system, thus causing the $2 \mathrm{D}$ head ejection envelopes to be normal to both the vehicle and the barrier. Also, the barriers used in this study had vertical, or near vertical, front-face geometries. Thus, the envelope origins, or the bottom of the side windows, for each vehicle lay on the same vertical plane. Therefore, only the height to the bottom of the side window was needed to combine the individual envelope boundaries obtained for small cars and pickup trucks.

Although the vehicles within each test group were similar in size, the height to the bottom of the side window can vary by a few inches between vehicle models. The small car ejection enve- lope represents the lower boundary for the total envelope and its origin is based upon the vehicle's window height. Lower window heights enlarge the envelope and, therefore, the lowest height for the small car vehicle class was utilized for constructing the overall envelope. Similarly, the lower portion of the truck head ejection envelope enlarges the overall envelope as the height to the bottom of the window is reduced. Therefore, the lower boundaries for both small cars and pickup truck ejection envelopes were placed at the lowest window height for their respective vehicle classes. However, the top of the overall ejection envelop is defined by the pickup truck's upper envelope boundary. Raising the height of the upper boundary increases the size of the overall envelope. Hence, the pickup truck upper boundary was located to correspond with the tallest window height in the vehicle class to ensure that the final envelope encompassed as wide a range of vehicles as possible.

Finally, the head ejection envelope must be applicable to all vehicle models and not just those used in the crash tests. Window heights for a wide range of vehicles were sampled in an effort to identify the full-range of window height distributions in vehicle fleet. The first measurements were taken at the Midwest Roadside Safety Facility's outdoor test site from vehicles meeting NCHRP Report No. 350 test vehicle criteria. The measurement of actual test vehicles was considered a priority because: (1) much of the ejection data was collected from small car test vehicles and (2) these vehicles represent the smallest vehicles on the roadway today. New vehicles from the 2006 model year that were close to the test vehicle classifications were also measured at local car dealerships including Ford, Chevrolet, Dodge, Saturn, Nissan, Honda, and Toyota models.

Whenever possible, multiple vehicles for each make and model were measured to gather a large array of vehicle data. The vehicle investigation revealed a minimum height to the bottom of the side window of $914 \mathrm{~mm}$ (35 in.) for small cars and 1245 $\mathrm{mm}$ (49 in.) for pickup trucks. The maximum height to the bottom of a pickup side window was $1372 \mathrm{~mm}$ (54 in.).

The initial shape of the combined head ejection envelope was created by shifting the three envelope boundaries to the correct locations. The initial overall head ejection envelope is illustrated in Figure 5(a). Note that a vertical-face barrier was assumed for the illustration.
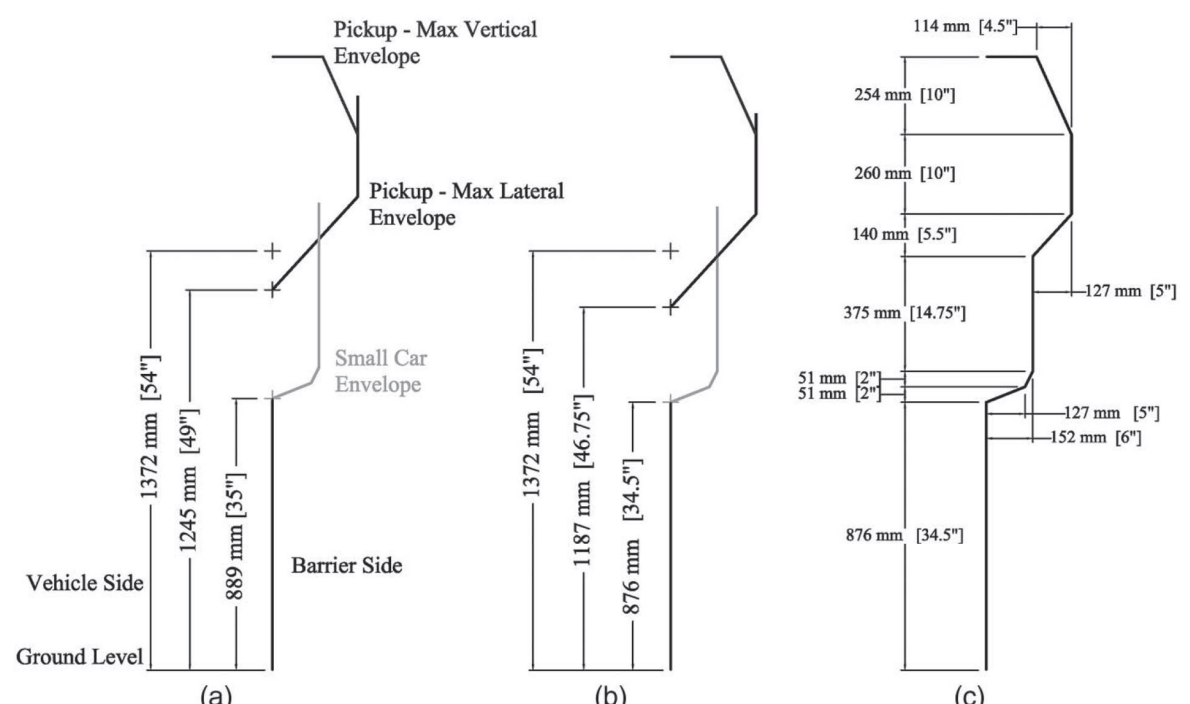

(a)

(b)

(c)

Figure 5. (a) Assembly of initial combined head ejection envelope; (b) combined head ejection envelope incorporating vehicle movement during impact; and (c) dimensioned envelope incorporating vehicle movement 


\section{Envelope Adjustments for Vehicle Movement}

Head ejection measurements were made relative to the bottom of the vehicle's side window, and the height to the window was determined from vehicle measurements. However, vehicle motions, such as body roll toward the barrier, could lower the window height and may lead to head ejection outside of the envelope boundaries shown in Figure 5(a). Therefore, window heights taken from stationary vehicles needed to be adjusted for movement during the impact event.

The expected magnitude and direction of vehicle roll is dependent on the shape of the barrier. For example, safety shape concrete barriers allow vehicles to climb the barrier face during impact. Vehicle climb raises the impact side of the vehicle and causes it to roll away from the barrier. Vertical-faced barriers, on the other hand, produce little to no climb and tend to cause impacting vehicles to roll slightly toward the barrier. Only roll toward the barrier will lower the vehicle's side window height and adversely affect the boundaries of the head ejection envelope. Further, impacts with vertical-faced barriers cause more severe ejections and set the limits for the head ejection envelope. Therefore, alterations to the head ejection envelope to account for vehicle motion were taken from vertical movement of vehicle side windows during impacts with vertical-faced barriers.

In most cases, the crash test videos used to measure head displacements were also used to measure vehicle movements. All four of the selected small car test videos and two of the four selected pickup truck test videos were used to determine vertical window movements during head ejection events. Two of the original pickup truck videos that were used to measure head displacement consisted of impacts with semirigid barriers. These tests were not believed to provide valuable results for use in adjusting for vehicle movements. Therefore, videos from two additional crash tests that did not incorporate the use of a dummy, were added to observe the effects of a pickup truck impacting a vertical-faced rigid barrier (Pfeifer et al. 1996; Holloway et al. 1996).

By using the downstream camera view, the vertical distance from the bottom of the vehicle's side window to a stationary point was measured, first at impact, and then again at the time of maximum head ejection. For the two tests without a dummy, the second measurement was taken when the vehicle was parallel with the barrier. Similar to the initial video analysis, all measurements were repeated to times to estimate the range of possible measurement error. Vehicle movement measurements are listed in Table 2.

A small downward movement of the side window was observed in all small car tests. A maximum downward displacement of approximately $13 \mathrm{~mm}$ (0.5 in.) was recorded during crash test Nos. I2-3 and 418048-5. As a result, the boundary de-

Table 2. Measured Vertical Movement of Side Window during Impact

\begin{tabular}{llrrrrr}
\hline & & \multicolumn{2}{c}{$\begin{array}{c}\text { Measurement } \\
\text { average }\end{array}$} & & \multicolumn{2}{c}{$\begin{array}{c}\text { Maximum } \\
\text { vertical shift }\end{array}$} \\
\cline { 3 - 4 } Test No. & Vehicle type & $(\mathrm{mm})$ & (in.) & & $(\mathrm{mm})$ & (in.) \\
\hline $418048-4$ & Small car & -2.1 & -0.08 & & -7.1 & -0.28 \\
$418048-5$ & Small car & -6.7 & -0.26 & & -12.1 & -0.48 \\
I2-3 & Small car & -5.4 & -0.21 & & -13.5 & -0.53 \\
$404311-1$ & Small car & 1.7 & 0.07 & & -5.8 & -0.23 \\
$404201-8$ & Pickup & -43.6 & -1.72 & & -45.1 & -1.78 \\
$401021-1$ & Pickup & -50.6 & -1.99 & & -57.1 & -2.25 \\
MN-3 & Pickup & -10.6 & -0.42 & & -35.4 & -1.39 \\
NEOCR-5 & Pickup & -38.2 & -1.50 & & -57.3 & -2.26 \\
\hline
\end{tabular}

scribing the head ejection envelope for small cars was lowered by $13 \mathrm{~mm}$ ( $0.5 \mathrm{in}$.) to accommodate the worst-case conditions identified during crash testing.

Crash test videos of pickup trucks impacting rigid concrete barriers also showed a relatively consistent behavior. A maximum downward displacement of approximately $57 \mathrm{~mm}$ (2.25 in.) was recorded. Thus, the boundary describing the lower portion of the head ejection envelope for pickup trucks was lowered by $57 \mathrm{~mm}$ (2.25 in.). Figures 5(b) and 5(c) depict the head ejection envelope after adjustments were made to account for vertical movement of the side window during impact events. Note that the upper boundary of the ejection envelope was not adjusted to assure that the envelope would accommodate impacts where the pickup truck does not roll toward the barrier.

\section{Envelope Adjustment for Midsize Vehicles}

Thus far, the head ejection envelope has been founded on small car and pickup truck impacts without consideration for midsize vehicles. Here, "midsize vehicles" refers to sedans, smaller SUVs, small pickups, and other vehicles falling in between the size requirements for small cars and full-size pickup trucks recommended for use in crash testing by NCHRP Report No. 350. These other vehicle types must be included in the head ejection envelope to assure safe barrier performance for the full-range of passenger vehicles.

Because midsize vehicles are not recommended as crash test vehicles by NCHRP Report No. 350, very few full-scale crash tests have been performed with these vehicles. Thus, it is not surprising that no crash test videos showing head ejection from a midsize vehicle could be found. Therefore, the head ejection from
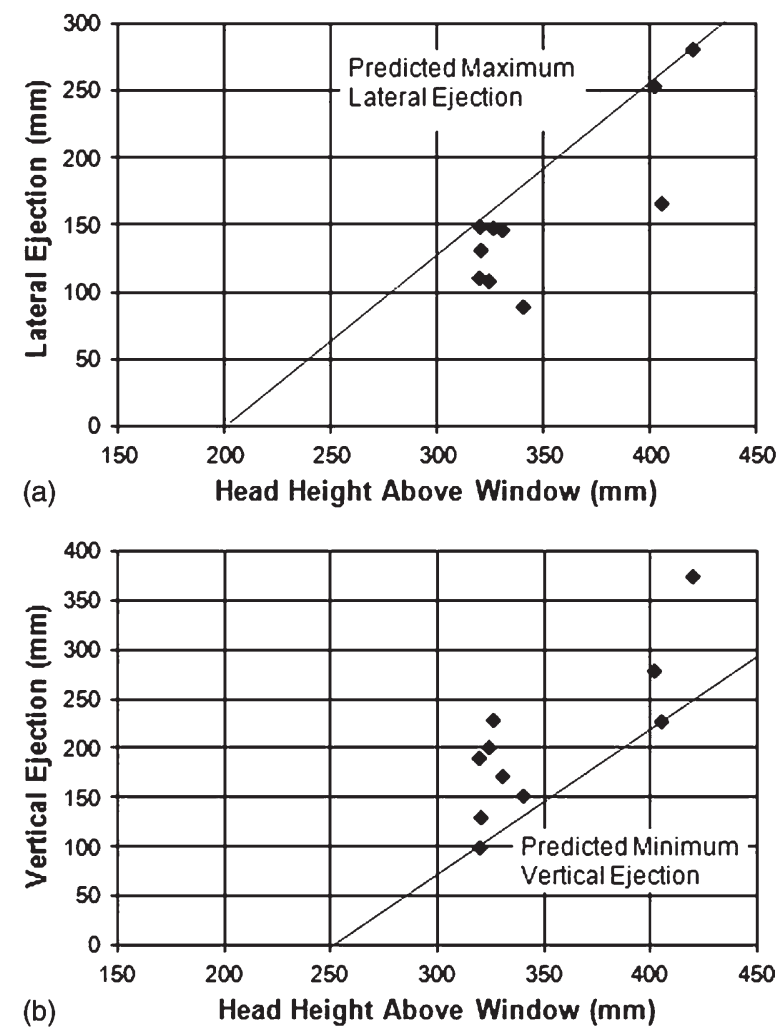

Figure 6. Data and boundary lines for maximum ejection point versus head height in: (a) lateral; (b) vertical directions 
midsize vehicles had to be interpolated from the head ejection observed in small car and pickup truck impacts.

The primary difference in head ejection behavior observed in small car and pickup trucks impacts is the seated position of the occupants in these vehicles. As explained previously, a pickup truck passenger is seated more upright and in a higher position relative to the side window when compared to a small car passenger. Ejections from small cars were lower vertically, and in some cases, restricted from further movement by the bottom of the side window. Ejections from pickups were not only higher vertically but also extended out farther laterally. The increase in the vertical position of the passenger with respect to the side window increases both the maximum lateral head displacement and increases the vertical position of the head at the moment of maximum lateral displacement.

Seating positions for passengers of midsize vehicles are generally somewhere between those found for small cars and pickup truck passengers. Thus, midsize vehicle occupants would be subjected to greater lateral head displacements than observed for small car occupants but lower lateral head displacements than observed for pickup truck occupants. To quantify the head ejection displacements of midsize vehicles, both the maximum lateral head ejection and the minimum vertical head position were assumed to be linear functions of the head height above the bottom of the side window.
To determine these linear functions, it was necessary to reference the dummy head heights relative to the side windows for the crash tests listed in Table 1 . The distances from the bottom of the side windows to the top of the dummy's head were measured for each crash test. A plot was then made of lateral head ejection as a function of head height above the side window base. A line was drawn over the top of all the data points representing a linear boundary for maximum lateral head ejection versus height from the bottom of the window. This line should provide a conservative estimate of the maximum head ejection distance for any head height above the side window. The equation for the linear interpolation was found to be

$$
L_{\max }(\mathrm{mm})=33.53 \times h(\mathrm{~mm})-271.53
$$

or

$$
L_{\max }(\text { in. })=1.32 \times h(\text { in. })-10.69
$$

where $L_{\max }=$ maximum lateral head ejection; and $\mathrm{h}=$ head height above the bottom of the side window. A more detailed description of the construction of this interpolation equation is presented in Rosenbaugh (2007).

The same process was repeated for the vertical position of the head at maximum ejection. A plot was constructed of vertical location of maximum head ejection as a function of head height above the side window, and a boundary line was drawn.

Table 3. Vehicle Measurements and Head Height Results-50th Percentile Male

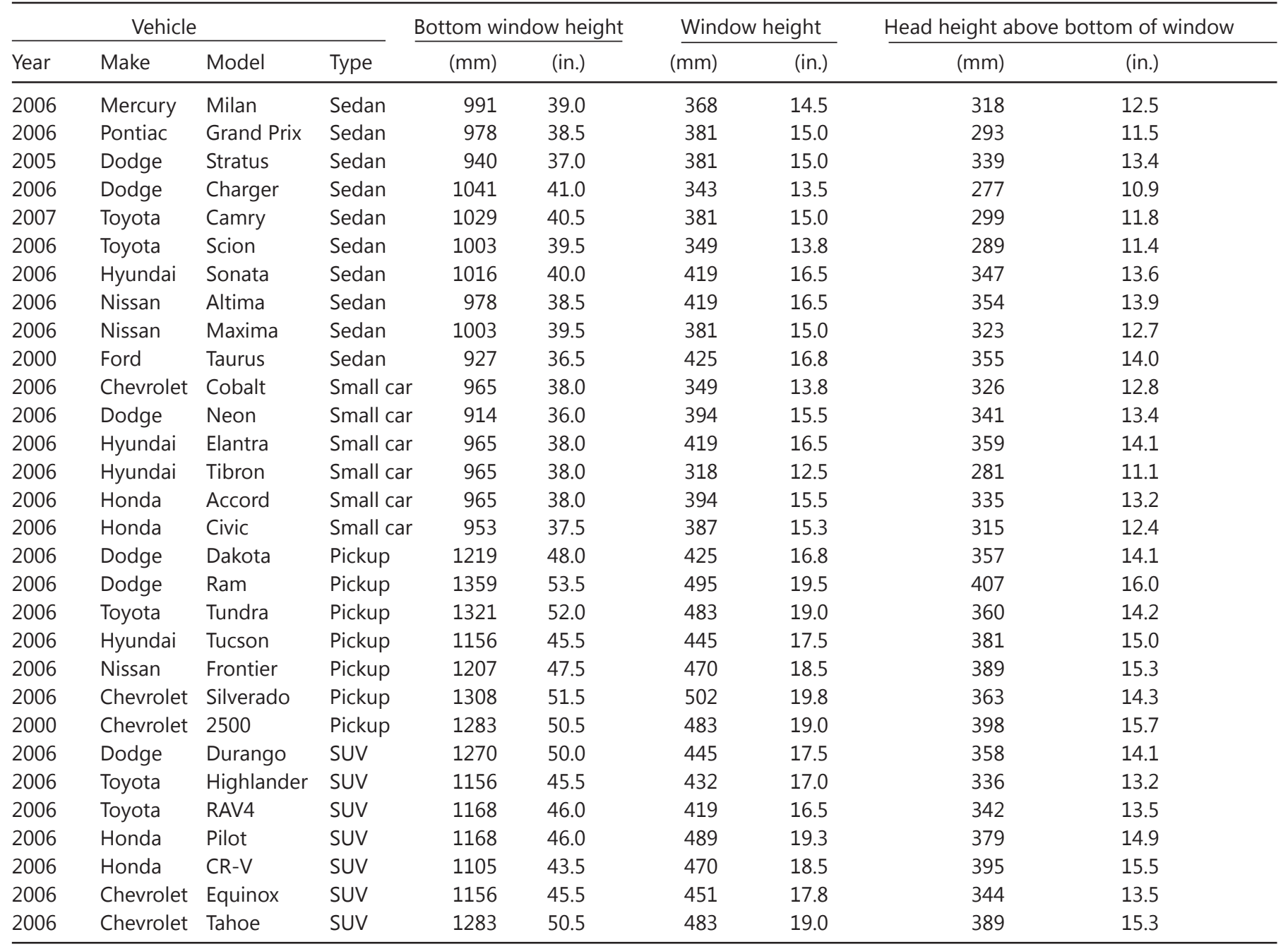


This time, the line was drawn under the data points because the lower bound vertical position was deemed critical for small car and midsize vehicles. The interpolation equation for the vertical location for maximum head ejection position was best described as shown in the following equations:

$$
V_{\text {min }}(\mathrm{mm})=39.88 \times h(\mathrm{~mm})-409.45
$$

or

$$
V_{\min }(\text { in. })=1.57 \times h(\text { in. })-16.12
$$

where $V_{\min }$ is the minimum vertical distance measured from the bottom of the window to the point of maximum head ejection. Figure 6 shows the data plots and boundary lines for both the maximum lateral and minimum vertical ejection locations.

The maximum lateral head ejection and the corresponding vertical head position, point No. 3 in the displacement measurements, were used for the interpolation equation because the midsize vehicles only define the middle portion of the ejection envelope. The upper bound, or return path of the head, was not needed because the full-size pickup truck defined the upper portion of the envelope during rebound. Similarly, the lower contours of the head ejection envelope were defined by the small car.

To obtain head heights above the windows of midsize vehicles, an MwRSF staff member, whose seated height matched that of a 5oth percentile male dummy, was measured while positioned in the driver's seat of a wide range of vehicles. Measurements for head height, side window height, and height to the bottom of the window were recorded for new midsize vehicles found at Chevrolet, Dodge, Ford, Hyundai, Nissan, Honda, and

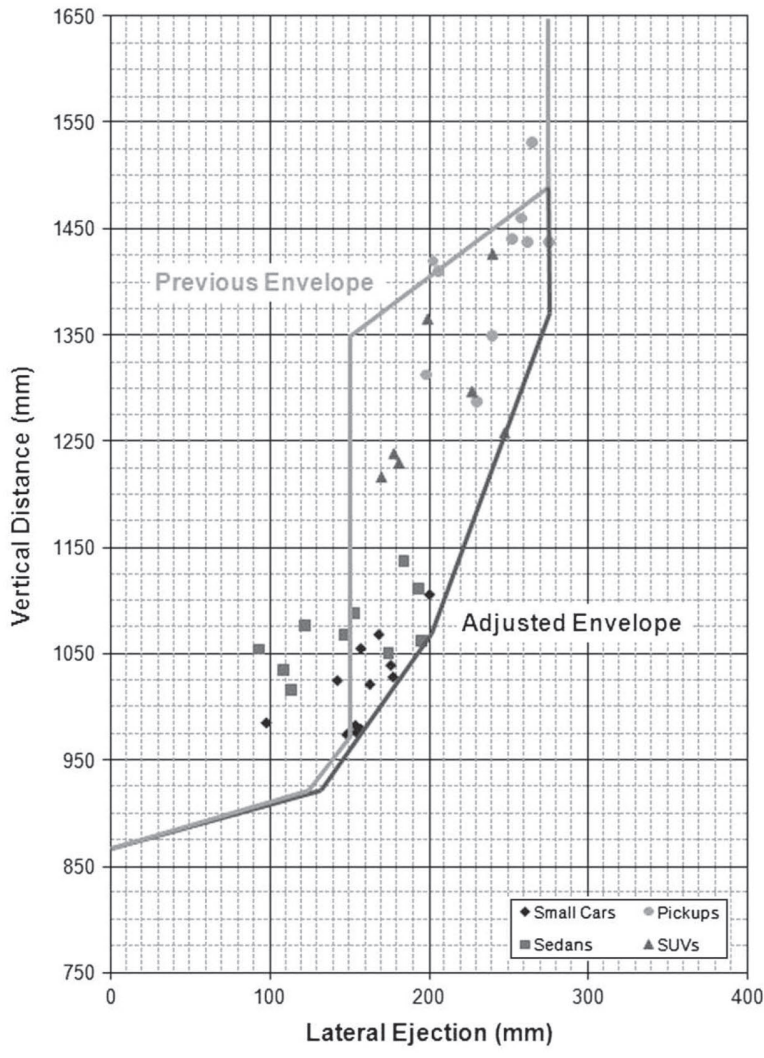

(a)
Toyota dealerships. Each distance was measured five times, and the averages were used to calculate the head height. The vehicle and head height measurements are shown in Table 3.

The calculated head heights were then entered into the linear interpolation equations to find the maximum lateral and minimum vertical ejection displacements. The head heights obtained from crash test vehicles, and associated videos, were also entered into the interpolation equations to determine the worst case scenario and to better define the boundaries of the head ejection envelope. Although the maximum lateral head displacement was calculated solely by using Equation (1), the vertical head position required further shifting. The height to the bottom of the side window of each vehicle was added to the predicted vertical ejection found by using Equation (2). Then, the predicted vertical movement of the vehicle during impact was subtracted. Because no crash test videos nor test data could be found on the vertical movement of midsize vehicles, the vertical movement found for small cars was applied to sedans, and the movement for pickup trucks was applied to SUVs. Thus, every small car and sedan was given a vertical window drop of 13 $\mathrm{mm}$ ( 0.5 in.), and every pickup and SUV was given a drop of 57 $\mathrm{mm}$ (2.25 in.).

Figure 7 contains a scatter plot of the predicted maximum head ejection data for midsize vehicles. The initial head ejection envelope from small car and pickup truck impacts is denoted by the lighter line segments. A new head ejection envelope was drawn to encompass head ejections for all vehicle classes, as denoted by the dark line segments. The adjusted shape was then combined with the remaining envelope boundaries to form the final, 5oth percentile male, head ejection envelope.

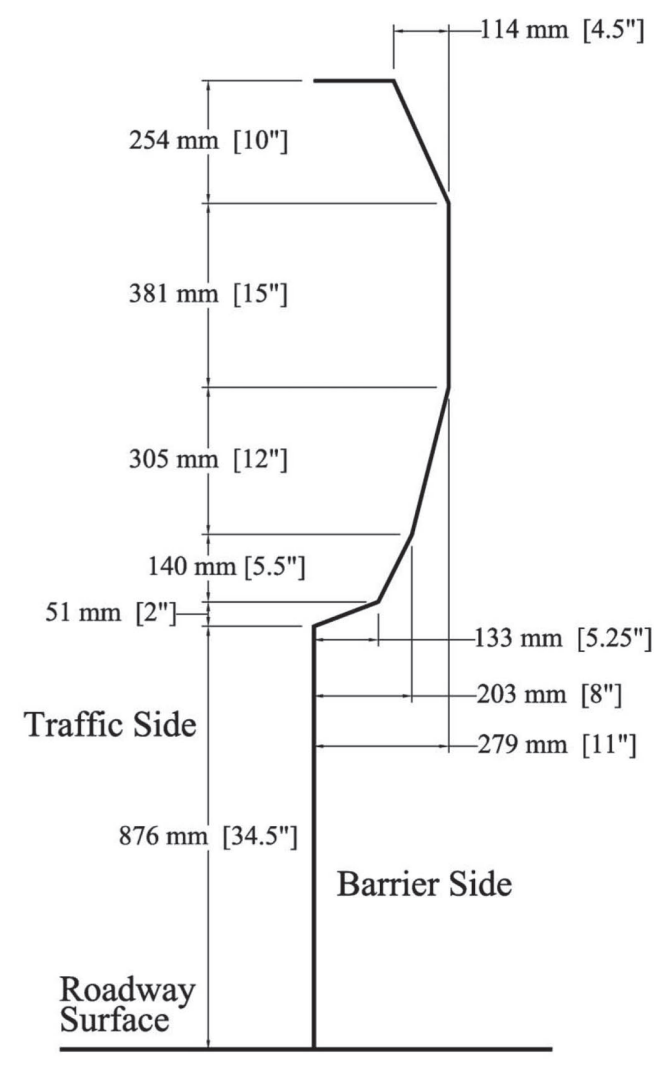

(b)

Figure 7. (a) Predicted maximum ejections and the adjusted envelope; (b) dimensions of finalized 5oth percentile male head ejection envelope 


\section{Head Ejection Envelope Based on 95th Percentile Male}

The final head ejection envelope, as provided in Figure 7, was developed by using measurements from the Hybrid III 5oth percentile male dummy and from a real person with a comparable seated height to that dummy. However, it should be noted that vehicle passengers are often taller than the height represented by the 5 oth percentile male. In these situations, a taller passenger would actually be positioned higher in a given vehicle seat, thus resulting in the propensity for greater head ejection displacements than those provided in Figure 7.

To adjust the head ejection envelope to consider taller vehicle occupants, it was necessary to determine the target size of the larger passenger and the corresponding seated passenger height in various vehicles. For this study, the researchers selected a Hybrid III 95th percentile male dummy as the target height of a taller occupant and for use in modifying the head ejection envelope. A 95th percentile male dummy has a seated height of 935 $\mathrm{mm}$ (36.8 in.) measured from the seat to the top of the head. On the contrary, a 5oth percentile male dummy has a seated height of $884 \mathrm{~mm}$ (34.8 in.), thus resulting in a $51 \mathrm{~mm}$ ( 2 in.) difference between seated heights for the 5oth and 95th percentile male dummies. Therefore, the occupants heights denoted in Table 3 were increased by $51 \mathrm{~mm}$ ( 2 in.) to adjust for the use of a 95th percentile male. In several cases, this change resulted in a higher seated height than the height measured to the top of a vehicle's side window. For these circumstances, the height adjustment was deemed impractical, because the lateral motion of the occupant's head would be restricted by contact with the top of the window frame. Therefore, the full height of the side window was selected as the seated occupant height for these situations. Once the 95th percentile occupant seated heights were de- termined, these heights were entered into Equations (1) and (2) to calculate the maximum lateral head displacements and corresponding vertical head positions. A more detailed description of this adjustment is presented in Rosenbaugh (2007).

The head ejection envelope was then modified and expanded to include all the calculated 95th percentile head ejection data. Also, the upper limit of the head ejection envelope was shifted up $51 \mathrm{~mm}(2 \mathrm{in}$.) to match the increase in seated height. A comparison between the lateral ejection limits for both the 5oth percentile male and the 95th percentile male are shown in Figure 8(a), whereas dimensions for the final 95th percentile male head ejection envelope are given in Figure 8(b).

\section{Summary and Conclusions}

For this study, researchers examined the trajectory of a belted occupant's head out of the side windows of vehicles during oblique impacts with longitudinal barriers. This investigation was accomplished through analysis of high-speed videos from full-scale crash tests involving both small cars and pickup trucks impacting rigid and semirigid longitudinal barriers. Upstream, downstream, and overhead camera views were utilized to track the trajectory of ejected heads in both the lateral and vertical directions, by using the bottom of the vehicle side window as a reference point.

Data from eight small car tests was compiled into a single plot, and boundary lines were drawn to encompass all the head positions in both the maximum lateral and minimum vertical directions. Similarly, data from three pickup truck tests was compiled into a single plot, and two separate boundary envelopes were drawn. The first envelope contained the maximum lateral and minimum vertical head ejection, whereas the second envelope provided the maximum vertical boundary. The three sep-

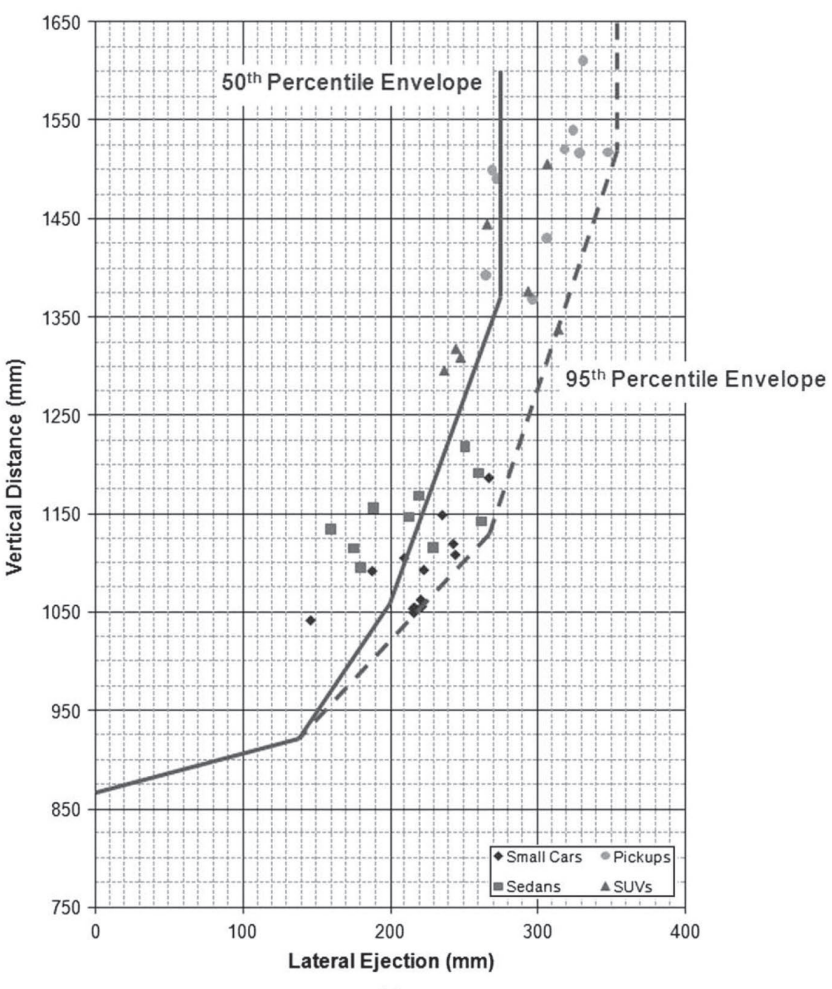

(a)

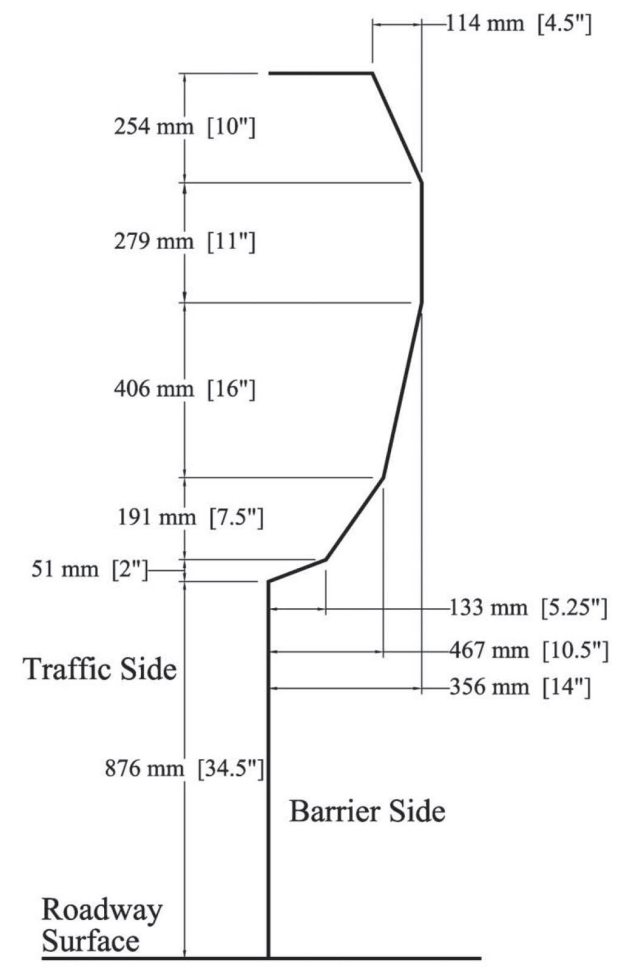

(b)

Figure 8. (a) Predicted 95th percentile male head ejection data and envelope bound adjustments; (b) dimensions of 95th percentile male head ejection envelope 
arate boundaries were then combined by placing them at critical side window heights, as measured from the current vehicle fleet. Adjustments were made to account for the downward vehicle motion attributable to roll during an oblique impact with a rigid vertical barrier.

An effort was made to extrapolate test results for head ejection to midsize vehicles. The maximum head displacement from these vehicles was predicted by using a linear interpolation between the measured maximum small car and maximum pickup head ejection data. The interpolation related the seated occupant height relative to the window to the maximum lateral ejection and the vertical location of maximum ejection out of the side window. The 5oth percentile male, head ejection envelope was finalized by adjusting the boundaries to encompass all measured and predicted data.

Finally, a second head ejection envelope was constructed to represent head locations of a taller occupant. The seated height of the 95th percentile male was utilized to include taller occupants. By using the same interpolation process to predict the head displacement for midsize vehicles, ejection limits were predicted for the 95th percentile male. A head ejection envelope was then created to encompass all the predicted head displacement data for an individual with a seated height equal to or less than a 95th percentile male.

The two head ejection envelopes, one founded on the seated height of a 5oth percentile male and the second founded on the seated height of a 95th percentile male, provide an objective tool for designing longitudinal barrier systems to prevent head slap. Implementation of these tools will greatly reduce the risk of head slap for any new vertical-face rigid barrier system.

The envelopes were developed for use as templates for configuring the upper geometry of rigid, longitudinal barrier systems. Because the envelopes were developed on a plane normal to the barrier surface, they should be placed directly on the traffic face of a new barrier cross section and applied throughout the length of the system. All upper barrier geometries greater than $876 \mathrm{~mm}$ (34.5 in.) and attachments, such as poles and signs, should be positioned to comply with the head ejection envelope, thereby ensuring increased passenger safety and protection against head slap.

The Update to NCHRP Report No. 350, now termed the Manual for Assessing Safety Hardware (MASH), recommends that all full-scale crash tests utilize a restrained dummy on the impacting side for tests in which an ejected head could impact the barrier or an attachment (Sicking et al. 2008). This new requirement should produce more crash tests involving head ejection from passenger vehicles impacting longitudinal barriers. As the MASH crash tests are conducted, the crash test data should be added into the existing database of head ejection measurements to refine the head ejection envelope. Because only three pickup truck tests were found showing significant head ejection, the addition of more head ejection data from pickup truck tests would be useful in either validating or refining the upper portion of the envelope boundaries.

Although the results of selected semirigid barrier testing were incorporated to supplement available test data, the head ejection envelope was primarily founded on rigid barrier testing. Thus, the head ejection envelope is not applicable to the design of flexible or semirigid barriers. Also, most of the collected crash test data pertained to impacts with barriers having vertical, or near vertical, front-face geometries. Rigid barriers with a mountable front-face, such as safety shape designs, allow impacting vehicles to climb the barrier face, thus raising the height of vehi- cle side windows and causing the vehicle to roll away from the barrier. For these barrier types, head ejection and the propensity for head slap would likely be reduced from that observed for impacts with vertical parapets. Thus, the current head ejection envelope is likely to be inappropriate for use in the design of tall barriers with mountable front faces.

Acknowledgments - The writers wish to acknowledge several sources that made a contribution to this project: (1) the Midwest State's Regional Pooled Fund Program for funding this study; and (2) the California Dept. of Transportation (CALTRANS) and the Texas Transportation Institute (TTI) for providing crash test videos and films.

\section{References}

Alberson, D. C., Menges, W. L., and Schoeneman, S. K. (2000). "NCHRP Rep. 350 Test 3-21 of the Ohio transition at non-symmetrical type 2 transition section." Rep. to Federal Highway Administration, Texas Transportation Institute, College Station, TX.

Buth, C. E., Menges, W. L., and Butler, B. G. (1998a). "NCHRP Rep. 350 test 3-21 of the vertical flared back transition." Rep. to Federal Highway Administration, Rep. No. FHWA-RD-98, Texas Transportation Institute, College Station, TX.

Buth, C. E., Williams, W. F., Bligh, R. P., Menges, W. L., and Butler, B. G. (1998b). “Tests 4, 5, \& 6: NCHRP Rep. 350 testing of the Texas type T202 bridge rail." Rep. to Federal Highway Administration, Rep. No. FHWA/TX-99/1804-3, Texas Transportation Institute, College Station, TX.

Buth, C. E., Williams, W. F., Menges, W. L., and Schoeneman, S. K. (1998c). "NCHRP Rep. 350 test 4-10 of the Alaska multi-state bridge rail." Rep. for the Alaska Dept. of Transportation and Public Facilities, Rep. No. FHWA-RD-98, Texas Transportation Institute, College Station, TX.

Faller, R. K., Magdaleno, J. A., and Post, E. R. (1989). "Full-scale vehicle crash tests on the Iowa retrofit concrete barrier rail." Final Rep. to IA Dept. of Transportation, Transportation Research Rep. No. TRP-03-15-88, Univ. of Nebraska, Lincoln, Civil Engineering Dept., Lincoln, NE.

Giavotto, V. (2004). "Compatibility of vehicles with safety barriers: Head ejection through side windows.” Transportation Research Record, No. 189o, Transportation Research Board, National Research Council.

Holloway, J. C., Faller, R. K., Wolford, D. L., and Sicking, D. L. (1996). "Performance level 2 tests on a 29-in. open concrete bridge rail." Final Rep. to the NE Dept. of Roads, Project SPR-3(o17), Transportation Rep. No. TRP-03-51-95, Midwest Roadside Safety Facility, Univ. of Nebraska, Lincoln, Lincoln, NE.

Jewell, J. R. (1997). "Vehicle crash tests of a slip-formed, single slope, concrete median barrier with integral concrete glare screen." Rep. No. FHWA/CA/ESC-98/o2, California Dept. of Transportation, Division of New Technology.

Jewell, J., Payam, R., Meline, R., and Peter, R. (1998). "Vehicle crash tests of the type 70 bridge rail." Final Rep. to Federal Highway Administration, Rep. No. FHWA/CA/ESC-98/o6, California Dept. of Transportation, January 1998.

Meline, R., Jewell, J., and Peter, R. (1999). "Vehicle crash tests of the type 80 bridge rail." Final Rep. to Federal Highway Administration, Rep. No. FHWA/CA/ESC-98/o6 Part 3, Office of Materials and Foundations, California Dept. of Transportation. 
Menges, W. L., Buth, C. E., Williams, W. F., and Schoeneman, S. K. (2000). "NCHRP Rep. 350 test 4-11 of the Oregon 3-tube bridge rail." Rep. to Federal Highway Administration, Rep. No. FHWA$R D$-oo, Texas Transportation Institute, College Station, TX.

Michie, J. D. (1981). "Recommended procedures for the safety performance evaluation of highway appurtenances." National Cooperative Highway Research Program (NCHRP) Rep. 230, Transportation Research Board, Washington, DC.

Pfeifer, B. G., Holloway, J. C., Faller, R. K., and Rosson, B. T. (1996). "Test level 4 evaluation of the Minnesota combination bridge rail." Final Rep. to the MN Dept. of Transportation, Transportation Rep. No. TRP-03-53-96, Midwest Roadside Safety Facility, Univ. of Nebraska, Lincoln, Lincoln, NE.

Polivka, K. A., Faller, R. K., Holloway, J. C., Rohde, J. R., and Sicking, D. L. (2005). "Development, testing, and evaluation of NDOR's TL-5 aesthetic open concrete bridge rail." Final Rep. to the NE Dept. of Roads, Transportation Research Rep. No. TRP-03-14805, Midwest Roadside Safety Facility, Univ. of Nebraska, Lincoln, Lincoln, NE.
Rosenbaugh, S. K. (2007). "Development of a TL-5 vertical-faced concrete median barrier incorporating head ejection criteria." M.S. thesis, Univ. of Nebraska, Lincoln, Lincoln, NE.

Rosenbaugh, S. K., Sicking, D. L., and Faller, R. K. (2007). "Development of a TL- 5 vertical-faced concrete median barrier incorporating head ejection criteria." Transportation Research Rep. No. TRP-03-194-07, Midwest Roadside Safety Facility, Univ. of Nebraska, Lincoln, Lincoln, NE.

Ross, H. E., Sicking, D. L., Zimmer, R. A., and Michie, J. D. (1993). "Recommended procedures for the safety performance evaluation of highway features." National Cooperative Highway Research Program (NCHRP) Rep. 350, Transportation Research Board, Washington, DC.

Sicking, D. L., Mak, K. K., Rohde, J. R., and Reid, J. D. (2008). "Recommended procedures for the safety performance evaluation of highway features." Draft Rep., Submitted to National Cooperative Highway Research Program, Project 22-14(2) Panel, Prepared by the Midwest Roadside Safety Facility, Univ. of Nebraska, Lincoln, Lincoln, NE. 